\title{
Is There Any Impact of VDR Gene Polymorphism in Bataks Ethnic to Have Tuberculosis?
}

\author{
Yahwardiah Siregar ${ }^{1}$ and Bintang Y.M. Sinaga ${ }^{2}$ \\ 1. Department of Biochemistry, Faculty of Medicine, Universitas Sumatera Utara, Medan, Indonesia \\ 2. Department of Pulmonology and Respiratory, Faculty of Medicine, Universitas Sumatera Utara-Adam Malik Hospital, Medan, \\ Indonesia
}

\begin{abstract}
The active metabolite of vitamin D activates macrophages and results in the restriction of growth of Tuberculosis (TB) pathogen M. tuberculosis. The effect of vitamin D is achieved through binding to the Vitamin D Receptor (VDR), which ultimately produces the antimicrobial peptide Cathelicidin. Matched case-control study with 76 pulmonary tuberculosis Indonesian Batak ethnic patients and 76 healthy normal control were completed. Genetic polymorphisms of VDR gene were analysed using PCR and RFLP. The genotype frequencies of $\mathrm{ApaI}$ were AA 10.6\%, Aa 44.7\%, aa 44.7\% for the control group and AA 10.6\%, Aa 43.4\%, aa 46\% for the PTB patients. For the FokI genotype the frequencies were FF 39.5\%, Ff 44.7\%, ff $15.8 \%$ for the control group and FF $35.5 \%$, Ff $55.3 \%$, ff $9.2 \%$ for the PTB patients. In these two genotypes there were no significant differences found between the control group and the PTB patients $(P>0.05)$. Besides, there genotypic frequencies were in agreement with the Hardy-Weinberg Equilibrum $(P>0.05)$. However, for the $B s m$ I genotype frequencies, BB $2.6 \%$, Bb $23.7 \%$ and bb $73.7 \%$ for the control group and $\mathrm{BB} 0 \%, \mathrm{Bb} 68.4 \%$, bb $31.6 \%$ for the PTB patients, there was a significant association found with PTB; the bb genotype is correlated with a decreased risk for PTB (OR 0.22, 95\% CI: 0.11-0.45). ApaI and FokI polymorphisms of VDR gene do not appear to be responsible for host susceptibility to pulmonary tuberculosis in the Indonesian Batak ethnic population but BsmI polymorphism had association with host resistant to PTB.
\end{abstract}

Key words: Pulmonary tuberculosis, VDR polymorphism, Batak, Indonesia.

\section{Introduction}

Tuberculosis (TB) is a contagious disease that remains one of the world's deadliest health problems to date. The World Health Organization (WHO) reported in 2013 that is was estimated that 9 million people worldwide suffer from TB, of which $56 \%$ of the cases occur in South East Asia and West Pacific, and that 1.5 million deaths yearly are caused by TB [1]. Among several other transmission diseases, Pulmonary tuberculosis (PTB) is considered a high burden in Indonesia. After infection of the pathogen which is responsible for TB, Mycobacterium tuberculosis, it is known that environmental and host genetic factors can influence the susceptibility to develop active TB $[2,3]$. Many studies were able to produce convincingly prove

Corresponding author: Yahwardiah Siregar, Dr. Med., research field: Vitamin D and VDR-gene. that the genetic factor plays an important role in the disease enhancement [3, 4]. Recently, researches are focusing on the Vitamin D Receptor (VDR), which caught the interest as it was shown that the growth of $M$. tuberculosis is restrained after vitamin $\mathrm{D}$ administration $[4,5]$. This effect is achieved through the binding of vitamin D to VDR located in macrophages, which activates the antimicrobial peptide cathelicidin synthesis [4], and consequently eliminates Mycobacterium tuberculosis in the phagolysosome [5]. This process and therefore the effect of vitamin $\mathrm{D}$ might be influenced by polymorphisms in the VDR gene.

One of these polymorphism is FokI, with a transition of C to T (ACG-ATG) at the first of the two potential translation initiation sites in exon 2, and can be distinguished by RFLP using endonuclease FokI. If translation start at the primary ATG site, individuals with the $\mathrm{T}$ allele designed as $\mathrm{f}$, the VDR protein is 
synthesized in the full-length of 427 amino acids. In contrast, if the translation start at the second ATG site, individuals with the $\mathrm{C}$ allele designed as $\mathrm{F}$, the VDR protein lacks three NH2-terminal amino acids [6]. Several studies showed that the transcription of the $\mathrm{F}$ allele occurs 1.7 times more than the $f$ allele and that the $\mathrm{F}$ allele interacts with the transcription factor IIB more efficiently, resulting in a more potent VDR protein transcription [7, 8]. The second polymorphism in this study is BsmI, which is located at the intron between exon VIII and IX. The BsmI polymorphism control transcription level, transcription stability and post modification transcription of VDR gene [9]. The final investigated polymorphism is ApaI located at intron 8 with a transtition of $\mathrm{T}$ to $\mathrm{G}$. The term $\mathrm{A}$ indicates the $\mathrm{T}$ allele and a the $\mathrm{G}$ allele [4]. Apa $\mathrm{I}$ variation could generate splicing errors henced affect to the protein synthesis.

The potential roles of VDR FokI, ApaI and BsmI polymorphisms in the occurence of PTB have been investigated in many ethnic groups. Different outcome of results produced by this studies are probably due to the diversities of the ethnic groups. A meta analysis study performed by Gao et al. in 2010, found that in Asians, the subjects with ff genotype were more susceptible to PTB and the subjects with bb genotype have a decrease risk for PTB. However, none of the polymorphisms was significantly related to PTB among Africans or South Americans [10]. For the BsmI polymorphism in the European population, the variant homozygote and heterozygote genotypes were associated with a significantly decreased risk of tuberculosis when compared to the wild type homozygote [11]. ApaI polymorphism has no influence in the levels of VDR protein among 65 pulmonary tuberculosis (PTB) patients and 60 normal healthy subjects in Chennai, India [12]. Because the genetic effect may be different in various ethnic groups, this study wanted to investigate the effect of VDR polymorphism on PTB susceptibility in the Indonesian Batak-ethnic population.

\section{Methods}

\subsection{Cases and Controls}

Pulmonary tuberculosis patients were recuited from several TB services in Medan city, Indonesia, from November 2012 to April 2013. The cases were newly diagnosed pulmonary tuberculosis patients, age 16-55 years old, Batak ethnic, have symptoms of pulmonary $\mathrm{TB}$, positive sputum smear and chest radiography consistent with active disease. Cases who were HIV positive and known to present diabetes mellitus and other severe disease, imunnosupressive drug consumption were excluded from the study.

A control group composed of sex, age and ethnically matched were healthy subjects with normal chest X ray and no history of previous tuberculosis. A control group were healthy workers like doctors, nurses and medical students. All participants were from the Batak ethnic for 3 generations. This study was approved by the Ethics Committee of the Faculty of Medicine, University of Sumatera Utara, Medan, Indonesia.

\subsection{VDR Genotyping}

All subjects were interviewed and an informed consent was obtained. An anticoagulated peripheral blood specimen was collected and DNA was extracted (Promega, USA) and stored at minus $20{ }^{\circ} \mathrm{C}$. Polymerase Chain Reaction (PCR) and Restriction Fragment Length Polymorphism (RFLP) was used to identify ApaI, FokI and BsmI polymorphism of the Vitamin D Receptor gene. The primer sequences used in this study were as follows: Forward primer: AGA GCA TGG ACA GGG AGC AAG; Reverse Primer: GCA ACT CCT CAT GGC TGA GGT CTC A for ApaI, Forward Primer: 5'-AGC TGG CCC TGG CAC TGA CTC TGC TCT-3' and Reverse Primer: 5'-ATG GAA ACA CCT TGC TTC TTC TCC CTC-3' for FokI [13]. Forward Primer: 5'-CAA CCA AGA CTA CAA GTA CCG CGT CAG TGA-3' and Reverse Primer: 5'-AAC CAG CGG GAA GAG GTC AAG GG-3' for BsmI [13]. 
PCR conditions were as follow; for FokI and Bsm I was denaturation at $94{ }^{\circ} \mathrm{C}$ for $5 \mathrm{~min}$, followed by 35 cycles of PCR at $94{ }^{\circ} \mathrm{C}(30 \mathrm{~s})$, annealing at $61{ }^{\circ} \mathrm{C}(30 \mathrm{~s})$, and $72{ }^{\circ} \mathrm{C}(1 \mathrm{~min})$ [13]. ApaI proceed through 40 cycles of PCR at $94{ }^{\circ} \mathrm{C}(30 \mathrm{~s})$, annealing at $60{ }^{\circ} \mathrm{C}(30 \mathrm{~s})$ and extension at $72{ }^{\circ} \mathrm{C}(30 \mathrm{~s})$. Final extension was continued at $72{ }^{\circ} \mathrm{C}$ for $7 \mathrm{~min}$. Following PCR, the amplified PCR products were digested with ApaI (NEB) restriction enzyme at $25{ }^{\circ} \mathrm{C}$ for $1 \mathrm{~h}$, FokI (Takara, Bio-Inc, Japan) restriction enzyme at $37{ }^{\circ} \mathrm{C}$ for $3 \mathrm{~h}$ and $B s m \mathrm{I}$ (Thermo Scientific, Lithuania) restriction enzyme at $37{ }^{\circ} \mathrm{C}$ for $4 \mathrm{~h}$ [13]. Digested products were analyzed using electrophoresis in $2 \%$ agarose gel and ethidium bromide stained. The bands were visualyzed by Gel Documentation System.

Depend on the digestion pattern of FokI polymorphism, individuals were scored as "ff" by homozygous for the presence of the FokI site (169 bp and $96 \mathrm{bp}$ ), "FF" homozygous for the absence of the FokI site (265 bp), or "Ff" in presence and absence of FokI site (265 bp, 169 bp and 96 bp) [13]. Digestion of the amplified 745 bp ApaI PCR product gives two fragments, $531 \mathrm{bp}$ and $214 \mathrm{bp}$ respectively, if the product was excessable. Depending on the digestion pattern, individuals were scored as "aa" homozygous for the presence of the ApaI site, "AA" homozygous for the absence of the ApaI site, or "Aa" in presence and absence of the ApaI site (745 bp, 531 $\mathrm{bp}$, and $214 \mathrm{bp}$ ). The digestion pattern of BsmI polymorphism were "bb" for the presence of Bsm I site (175 bp and $650 \mathrm{bp}$ ), "BB" homozygous for the absence of the BsmI site ( $825 \mathrm{bp}$ ), and "Bb" in presence and absence of the Bsm I site (825 bp, 175 bp and 650 bp) [13].

\subsection{Statistical Analysis}

The genotype frequencies of each of the SNPs were compared by the Chi-square test. The strength of the association between VDR ApaI, FokI and BsmI polymorphisms and TB risk was evaluated by calculating odds ratio (OR) with $95 \%$ confidence interval $(95 \% \mathrm{CI})$. The 2 -sided exact $P<0.05$ was considered statistically significant. Conditional logistic regression was performed to calculate the odds ratio. Data were managed and analysed using Epi info. Hardy-Weinberg equilibrium test was done in case and control groups for ApaI, FokI and BsmI polymorphisms using the web tool HWE Testing calculator, available on line; $P<0.05$ was considered as a significant disequilibrium [14].

\section{Findings}

The characteristics of PTB patients and normal control are summarized in Table 1. Sex, age and ethnic characteristics between PTB patients and controls were matched.

The results of VDR genotyping for PTB patients and healthy controls are summarized in Table 2 .

The characteristics of PTB patients and normal control are summarized in Table 1. There was no significant difference in sex, age and ethnic between PTB patients and controls $(P=1.000)$.

Table 1 Characteristic of PTB cases and controls group.

\begin{tabular}{llll}
\hline Characteristic & $\begin{array}{l}\text { Cases } \\
\mathrm{n}(\%)\end{array}$ & $\begin{array}{l}\text { Controls } \\
\mathrm{n}(\%)\end{array}$ & $P$ value \\
\hline Sex & $53(69.7)$ & $53(69.7)$ & 1.000 \\
\hline Male & $23(30.3)$ & $23(30.3)$ & \\
Female & & & 1.000 \\
\hline Age groups & $22(28.9)$ & $22(28.9)$ & \\
\hline $16-25$ & $32(42.1)$ & $32(42.1)$ & \\
$26-35$ & $14(18.4)$ & $14(18.4)$ & 1.000 \\
$36-45$ & $8(10.5)$ & $8(10.5)$ & \\
$46-55$ & $76(100)$ & $76(100)$ & \\
Ethnicity (Batak) &
\end{tabular}


Table 2 Allele frequencies and genotype of VDR gene ApaI, FokI and BsmI polymorphism in PTB cases and controls.

\begin{tabular}{|c|c|c|c|c|c|}
\hline Polymorphism & $\begin{array}{l}\text { Cases } \\
\mathrm{n}(\%)\end{array}$ & $\begin{array}{l}\text { Controls } \\
\mathrm{n}(\%)\end{array}$ & $P$ & $\begin{array}{l}\text { HWE in cases } \\
\chi^{2}(P)\end{array}$ & $\begin{array}{l}\text { HWE in controls } \\
\chi^{2}(P)\end{array}$ \\
\hline \multicolumn{6}{|l|}{ ApaI } \\
\hline Genotype AA & $8(10.6)$ & $8(10.6)$ & 0.987 & $0(>0.05)$ & $0.01(>0.05)$ \\
\hline $\mathrm{Aa}$ & $33(43.4)$ & $34(44.7)$ & & & \\
\hline aa & $35(46.0)$ & $34(44.7)$ & & & \\
\hline Total & $76(100)$ & $76(100)$ & & & \\
\hline \multicolumn{6}{|c|}{ Allele frequencies } \\
\hline A & $51(33.6)$ & $50(32.9)$ & 1.000 & & \\
\hline $\mathrm{a}$ & $101(66.4)$ & $102(67.1)$ & & & \\
\hline Total & $152(100)$ & $152(100)$ & & & \\
\hline \multicolumn{6}{|l|}{ Fok $\mathrm{I}^{13}$} \\
\hline Genotype FF & $27(35.5)$ & $30(39.5)$ & 0.314 & $2.67(>0.05)$ & $0.21(>0.05)$ \\
\hline $\mathrm{Ff}$ & $42(55.3)$ & $34(44.7)$ & & & \\
\hline $\mathrm{ff}$ & $7(9.2)$ & $12(15.8)$ & & & \\
\hline Total & $76(100)$ & $76(100)$ & & & \\
\hline \multicolumn{6}{|c|}{ Allele frequencies } \\
\hline $\mathrm{F}$ & $96(63.2)$ & $94(61.8)$ & 0.813 & & \\
\hline $\mathrm{f}$ & $56(36.8)$ & $58(38.2)$ & & & \\
\hline Total & $152(100)$ & $152(100)$ & & & \\
\hline \multicolumn{6}{|l|}{$B s m \mathrm{I}^{13}$} \\
\hline Genotype BB & 0 & $2(2.6)$ & $<0.001$ & $20.55(<0.05)$ & $0.14(>0.05)$ \\
\hline $\mathrm{Bb}$ & $52(68.4)$ & $18(23.7)$ & & & \\
\hline $\mathrm{bb}$ & $24(31.6)$ & $56(73.7)$ & & & \\
\hline Total & $76(100)$ & $76(100)$ & & & \\
\hline \multicolumn{6}{|c|}{ Allele frequencies } \\
\hline B & $52(34.2)$ & $22(14.5)$ & $<0.001$ & & \\
\hline $\mathrm{b}$ & $100(65.8)$ & $130(85.5)$ & & & \\
\hline Total & $152(100)$ & $152(100)$ & & & \\
\hline
\end{tabular}

HWE, Hardy- Weinberg Equilibrium; $P<0.05$ was considered as significant disequilibrium.

The results of VDR genotyping for PTB patients and healthy controls are summarized in Table 2. PTB patients and healthy controls has a similar distribution for ApaI genotype and allele frequencies $(P>0.05)$ and as well for FokI. On the BsmI genotype and allele frequencies, there was a significant difference between PTB patients and healthy controls $(P<0.001)$ [13]. The genotypes of ApaI, FokI polymorphism in cases and controls group were in Hardy-Weinberg equilibrium $(\mathrm{P}>0.05)$ and $B s m \mathrm{I}$ polymorphism in the control group as well. The Bsm I polymorphism case group was not in the Hardy-Weinberg equilibrium $(\mathrm{P}<$ 0.05) [13]. The relation between ApaI, FokI and Bsm I polymorphisms and pulmonary tuberculosis are summarized in Table 3.
There was no significant association found between the ApaI polymorphism and PTB (OR 0.98, 95\% CI: 0.33-2.91) for the Aa genotype and the aa genotype (OR 1.03, 95\% CI: 0.34-3.06). The relation of FokI polymorphism and PTB (OR 1.37, 95\% CI: 0.69-2.73) was also found not to be associated for Ff genotype and (OR 0.65, 95\% CI: 0.22-1.89) for ff genotype [13]. For the BsmI polymorphism, however the bb genotype did showed to be associated with a decreased risk to PTB (OR 0.22, 95\% CI: 0.11-0.45) [13].

\section{Discussion}

The development of active B after infection is depend on the multiply interaction between host, bacteria (agent) and environment. One of the host factors that 
Table 3 Analysis of VDR gene ApaI, FokI and BsmI polymorphisms in PTB cases and controls.

\begin{tabular}{|c|c|c|c|c|}
\hline Polymorphism & $\begin{array}{l}\text { Cases } \\
\mathrm{n}(\%)\end{array}$ & $\begin{array}{l}\text { Controls } \\
\mathrm{n}(\%)\end{array}$ & OR $(95 \% \mathrm{CI})$ & $P$ \\
\hline \multicolumn{5}{|l|}{ ApaI } \\
\hline Genotype AA & $8(10.6)$ & $8(10.6)$ & 1 & \\
\hline $\mathrm{Aa}$ & $33(43.4)$ & $34(44.7)$ & $0.98(0.33-2.91)^{*}$ & 0.964 \\
\hline aa & $35(46.0)$ & $34(44.7)$ & $1.03(0.34-3.06)^{*}$ & 0.964 \\
\hline \multicolumn{5}{|l|}{ Fok $^{13}$} \\
\hline Genotype FF & $27(35.5)$ & $30(39.5)$ & 1 & \\
\hline $\mathrm{Ff}$ & $42(55.3)$ & $34(44.7)$ & $1.39(0.69-2.77)^{*}$ & 0.352 \\
\hline $\mathrm{ff}$ & $7(9.2)$ & $12(15.8)$ & $0.64(0.22-1.86)^{*}$ & 0.418 \\
\hline \multicolumn{5}{|l|}{$B s m \mathrm{I}^{13}$} \\
\hline Genotype $\mathrm{BB}+\mathrm{Bb}$ & $52(68.4)$ & $20(26.3)$ & 1 & $<0.001$ \\
\hline $\mathrm{bb}$ & $24(31.6)$ & $56(73.7)$ & $0.22(0.11-0.45)^{*}$ & \\
\hline
\end{tabular}

*Odds ratio was calculated using conditional logistic regression analysis.

affect the susceptibility to PTB are genetics. Evaluation to some research showed that population or various ethnic gives different results. No significant relationship was found in this study between VDR ApaI and FokI polymorphism and PTB, which is the same result as in the population of Asia including Korea [15], India [16], China [10], and Iran [17], Africa [18-21] and South American population [22]. A meta analysis among the Asian population demonstrates that genotype $\mathrm{ff}$ was associated with susceptibility to TB [10]. Besides; association was found between the FokI polymorphism and TB in the Han population of China [23] and the males in India [24]. Another meta-analysis in China on the Han ethnic illustrates an association between the ff genotype of FokI polymorphism of VDR gene with PTB [25]. Also, a meta-analysis from 13 studies also confirmed the association between the ff genotype of FokI polymorphism with TB [26].

There is no correlation found between Bsm I polymorphism of the VDR gene and TB in studies from Africa [19, 30] and Asia including India [27] and Korea [25]. Other studies from Asia, including Iran [28] and Turki [29], and from Africa [30] showed that the bb genotype was a protective factor towards TB, while in another study, the bb genotype correlated to the susceptibility to TB in Iran [17, 31]. Among the Asian population using meta-analysis from 15 studies demonstrates that the $\mathrm{b}$ allele and bb genotype are associated with a decreased risk to TB [32]. For the BsmI polymorphism in the European population, the variant homozygote and heterozygote genotypes were associated with a significantly decreased risk of tuberculosis when compared to the wild type homozygote ( $b b+\mathrm{Bb}$ vs $\mathrm{BB})$ [11]. In the current related study, we found that bb genotype was associated with decreased risk to PTB [13].

Different results of this research compared to others, came from some reasoning. One of them is ethnic factor. Indonesia has more than 300 ethnics and this study restricted to Batak ethnic Indonesian population only, to prevent genetic bias from ethnic influence. Ethnicity is found to be very important factor on genetic function in PTB. ApaI polymorphism for PTB patients in Chennai, India was for $60.76 \%$ for the A allele and $39.23 \%$ for the a allele [12] and this was similar for $\mathrm{TB}$ in Bandung, Indonesia that was frequency of A allele $59.5 \%$ and for a allele was $40.5 \%$ [33] while frequency of A- and a- allele in Batak ethnic in Medan was differ, i. e 33.6\% and 66.4\% respectively. The distribution of FokI allele in the world diverge between populations or ethnics. Frequency of $\mathrm{F}$ allele in North Indian population was $71.5 \%$ and f allele was $28.5 \%$ [34], comparable to Chennai, India the frequency of $\mathrm{F}$ allele was $76.6 \%$ and f allele was $23.3 \%$ [12], whereas in one study (Batak ethnic in Medan, 
North Sumatera) the frequency of $\mathrm{F}$ allele was $61.8 \%$ and $f$ allelle was $38.2 \%$ [13] and this is vary from population in Bandung, Indonesia which is $22.6 \%$ for $\mathrm{F}$ allele and $77.4 \%$ for $f$ allele [33]. Frequency of $f$ allele is lower among African race (24\%) if compared to the Caucasians (34\%) and Asians (51\%) [35]. For BsmI polymorphism, the frequency of B allele in PTB patients in Chennai, India was $58.46 \%$ and for $\mathrm{b}$ allele was $41.53 \%$ [12] but in one linked to this study, the frequency of $\mathrm{B}$ allele and $\mathrm{b}$ allele were $34.2 \%$ and $65.8 \%$ respectively [13]. This results also vary form TB patients in Bandung, Indonesia, i.e. frequency of B allele was $14.3 \%$ and frequency of $b$ allele was $85.7 \%$ [33]. The frequency of B allele is 7\% among Asians, $36 \%$ among Africans and $42 \%$ among Caucasians [35]. Another studies found the Bsm I bb genotype frequency was 2\% among Asians, 5\% among Africa Americans and $17 \%$ among Caucasians [6].

The difference in classification of case and control in each study could also have altered the results. Some studies assume the case group as negative acid fast bacilli bacteria sputum or extra pulmonary TB, whereas for the control group, some studies took blood samples from blood banks where history of exposure to TB is not known. Correspondingly, not all studies have conducted HIV tests to determine the HIV status of the subjects [36]. A variety of results could also be caused by gene-environment interaction, gene-gene interaction and gene-agent interaction. In the Indian population, the levels of VDR protein were not fluctuate in both PTB patients and Normal Healthy Subjects (NHS) on polymorphism FokI but a trend towards decreased levels of VDR protein was observed in NHS with BB genotype compared to bb genotype of BsmI polymorphism [12]. In this study and one connected study [13], among those polymorphism $A p a \mathrm{I}$, FokI and BsmI, only bb genotype was associated to decreased risk for PTB. A study on Indian Gujarat ethnic resides in London showed no association between FokI polymorphism with TB, but together with vitamin D deficiency, ff genotype is associated with susceptibility to TB [37]. Another study in Bandung, Indonesia proved that $\mathrm{FF}$ and $\mathrm{Ff}$ genotype 2.94 more frequently found on Child TB than the healthy one [33]. Gene-gene interaction has been shown in some studies. A single gene that is not associated with susceptibility to TB will show an association if combined with other genes [38, 39]. Besides, gene-agent interaction showed association of a certain host gene with a certain strain of Mycobacterium tuberculosis [40, 41].

These results might also be affected by other factors. As a ligand of vitamin D, VDR could be activated if Vitamin D Receptor form heterodimer with Retinoid X Receptor (RXR) hence binding to Vitamin D Response Elements (VDRE) which are controlled by Vitamin D Response Elements-Binding Protein (VDRE-BP) on the gene target promoter of cathelicidin [5]. Cathelicidin promotes the elimination of $\mathrm{Mtb}$ in phagolysosome. It is known that before vitamin D enters the macrophage, inactive vitamin D in the blood serum could be bound to vitamin D binding protein (DBP) or stay in a free state. After inactive vitamin D bind to Toll-Like Receptor on macrophage, the CYP27b1 enzyme on mitochondria forms the active state of vitamin D. Consequently, along with heat shock protein 70 (hsc70) and bcl-2 associated athanogene (BAG-1), active vitamin D and its receptor enter the nucleus and forms heterodimer with Retinoid X Receptor (RXR) [5, 42]. Therefore, all that occur in transcription of cathelicidin can influence the results of the study.

\section{Conclusions}

The development of PTB is a complicate interaction between host, pathogen and environmental factors. From this study, which was performed in the Indonesian Batak ethnic population, revealed that ApaI gene of VDR polymorphism is not responsible for host susceptibility to PTB and in one related study FokI polymorphism as well [13]. Concerning the BsmI polymorphism [13], the bb genotype was associated 
with decreased risk to PTB. This outcome may give further clarification why some people are more resistant against TB than the others.

\section{Acknowledgments}

This study was partly supported by Directorate General of Higher Education, Ministry of Education and Culture, Indonesia (Hibah Bersaing Scheme; No. 4267/UN5.1.R/KEU/2013).

\section{References}

[1] WHO, 2014. Global Tuberculosis Report 2014. Available at http://www.who.int/TB/data. Accessed on December 5, 2014.

[2] Bellamy, R., Ruwende, C., Corrag, T., et al. 1998. "Variations in the NRAMP1 gene and susceptibility to tuberculosis in West Africans." N. Engl. J. Med. 338: 640-4.

[3] Buschman, E., Skamene, E., and Schurr, E. 2004. The role of the NRAMP1 gene in mycobacterial infection. In: Rom, W.N., Garay, S.M., ed. Tuberculosis. Lippincott William \& Wilkins, Philadelphia.

[4] Liu, P. T., Stenger, S., and Tang, D. H., et al. 2007. "Cutting edge: Vitamin D-mediated human antimicrobial activity against Mycobacterium tuberculosis is dependent on the induction of cathelicidin." J. Immunol. 179: 2060-3.

[5] Chun, R. F., Adams, J. S., and Hewison, M. 2008. "Back to the future: a new look at "old" vitamin D." $J$. Endocrinol. 198: 261-9.

[6] Zmuda, J. M., Cauley, J. A., and Ferrell, R. E. 2000. "Molecular epidemiology of vitamin D receptor gene variants." Epidemiol. Rev. 22: 203-17.

[7] Arai, H., Myamoto, K., Taketani, Y., et al. 1997. “A vitamin $\mathrm{D}$ receptor gene polymorphism in the tranlation initiation codon: Effect on protein and relation to bone mineral density in Japanese women.” JBMR. 12: 915-21.

[8] Jurutka, P. W., Remus, L. S., Whitfield, G. K., et al. 2000. "The polymorphic $\mathrm{N}$ terminus in human vitamin $\mathrm{D}$ receptor isoform influences transcriptional activity by modulating interaction with transcription factor IIB." Mol. Endocrinol. 14: 401-20.

[9] Kaleta, B., Bogaczewicz, J., Robak, E., et al. 2013. "Vitamin D Receptor gene BsmI polymorphism in Polish Patients with Systemic Lupus Erythematosus." ISRN Endocrinology. doi 10.1155/2013/427818.

[10] Gao, L., Tao, Y., Zhang, L., et al. 2010. "Vitamin D receptor genetic polymorphisms and tuberculosis: updated systematic review and meta-analysis." Int. J. Tuberc. Lung Dis. 14: 15-23.
[11] Chen, C., Liu, Q., Zhu, L., et al. 2013. "Vitamin D Receptor gene polymorphisms on the risk of tuberculosis, a meta-analysis of 29 case-control studies." PloS ONE. 8 (12): e83843. doi:10.1371/journal.pone.0083843. Volume 8 Issue 12.

[12] Selvaraj, P., Anand, P. S, Harishankar, M., and Alagarasu, K. 2009. "Plasma 1, 25 Dihydroxy Vitamin $D_{3}$ level and expression of vitamin D receptor and cathelicidin in pulmonary tuberculosis.” J. Clin. Immunol. 29: 470-8.

[13] Sinaga, B. Y. M., Amin, M., and Siregar, Y. 2014. "Correlation between Vitamin D Receptor Gene FokI and BsmI Polymorphisms and the Susceptibility to Pulmonary Tuberculosis in an Indonesian Batak-ethnic Population." The Indonesian Journal of Internal Medicine 46 (4): 275-82.

[14] Rodriguez, S., Gaunt, T. R., and Day lan, N. M. 2014. "Hardy-Weinberg equilibrium testing of biological ascertainment for Mendelian randomization studies." Available http://www.oege.org/software/hwe-mr-calc.html. Access on May 27, 2014.

[15] Kang, T. J., Jin, S. H., Yeum, C., et al. 2011. "Vitamin D receptor gene TaqI, BsmI and FokI polymorphisms in Korean patients with tuberculosis." Immune. Netw. 11: 253-7.

[16] Selvaraj, P., Kurian, S. M., Chandra, G., et al. 2004. "Vitamin D receptor gene variants of Bsm $\mathrm{I}, A p a \mathrm{I}, T a q \mathrm{I}$, and FokI polymorphisms in spinal tuberculosis." Clin. Genet. 65: 73-6.

[17] Banoei, M. M., Mirsaeidi, M. S., Houshmand, M., et al. 2010. "Vitamin D receptor homoxygote mutant $t t$ and $b b$ are associated with susceptibility to pulmonar tuberculosis in the Iranian population." Int. J. Infect. Dis. 14: e84-5.

[18] Bornman, L., Campbell, S. J., Fielding, K., et al. 2004. "Vitamin D receptor polymorphisms and susceptibility to tuberculosis in West Africa: A case-control and family study." J. Infect. Dis. 190: 1631-41.

[19] Lombard Z, Dalton DL, Venter PA, et al. 2006. "Association of HLA-DR, -DQ and vitamin D receptor alleles and haplotypes with tuberculosis in the Venda of South Africa." Hum. Immunol. 67: 643-54.

[20] Babb, C., van der Merwe, L., Beyers, N., et al. 2007. "Vitamin D receptor gene polymorphisms and sputum conversion time in pulmonanary tuberculosis patients." Tuberculosis (Edinb) 87: 295-302.

[21] Olesen, R., Wejse, C., Velez, D. R., et al. 2007. "DC-SIGN (CD209), pentraxin 3 and vitamin D receptor gene variants associate with pulmonary tuberculosis risk in West Africans." Genes Immun. 8: 456-67.

[22] Wilbur, A. K., Kubatko, L. S., Hurtado, A. M., et al. 2007. "Vitamin D receptor gene polymorphisms and susceptibility M. tuberculosis in Native Paraguayans." 
Tuberculosis. 87: 329-37.

[23] Liu, W., Cao, W., Zhang, C., et al. 2004. "VDR and NRAMP1 gene polymorphisms in susceptibility to pulmonary tuberculosis among the Chinese Han population: a case-control study." Int. J. Tuberc. Lung Dis. 8: 428-34.

[24] Selvaraj, P., Chandra, G., Kurian, S. M., et al. 2003. "Association of vitamin D receptor gene variants of BsmI, ApaI and FokI polymorphisms with susceptibility or resistance to pulmonary tuberculosis." Curr Sci. 84: $1564-8$

[25] Cao, S., Luo, P. F., Li, W., et al. 2012. "Meta analysis. Vitamin D receptor genetic polymorphisms and tuberculosis among Chinese Han ethnic group." Chin. Med. J. 125: 920-5.

[26] Su, Q., Ma, X. Y., Lin, H., et al. 2011. "Association between gene polymorphisms of vitamin D receptor and pulmonary tuberculosis susceptibility: a meta-analysis." Journal of medical colleges of PLA. 26: 67-75.

[27] Shing, A., Gaughan, J. P., and Kashyap, V. K. 2011. "SLC11A1 and VDR gene variants and susceptibility to tuberculosis and disease progression in East India." Int. J. Tuberc. Lung Dis. 15: 1468-4.

[28] Marashian, S. M., Farnia, P., Seyf, S., et al. 2010. "Evaluating the role of vitamin D receptor polymorphism on tuberculosis among Iranian patients: a case control study." Tuberk. Toraks. 58: 147-53.

[29] Ates, O., Dolek, B., Dalyan, L., et al. 2011. "The association between BsmI variant of vitamin D receptor gene and susceptibility to tuberculosis." Mol. Biol. Rep. 38: 2633-6.

[30] Fitness, J., Floyd, S., Wandorff, D. K., et al. 2004. "Large scale candidate gene study of tuberculosis susceptibility in Karonga district of Northern Malawi." Am. J. Trop. Med. Hyg. 71: 341-9.

[31] Merza, M., Farnia, P., Anoosheh, S., et al. 2009. "The NRAMP1, VDR and TNF- $\alpha$ gene polymorphisms in Iranian tuberculosis patients: the study on host susceptibility.” Braz. J. Infect. Dis. 13: 252-6.

[32] Wu, Y., Yang, X., Wang, X., et al. 2010. "Association of vitamin D receptor Bsm I gene polymorphism with risk of tuberculosis: A Meta-analysis of 15 studies." PloS ONE. 8 (6): e66944. doi: 10.1371/journal.pone.0066944.

[33] Setiabudiawan, B., Kartasasmita, C. B., Garna, H., Parwati, I., and Maskoen, A. M. 2010. $M K B$ 42: 4:187-93.

[34] Bid, H. K., and Mittal, R. D. 2003. "Study of vitamin D receptor (VDR) gene start codon polymorphism (FokI) in healthy individuals from North India." Indian Journal of Human Genetics 9 (2): 51-4.

[35] Uitterlinden, A. G., Fanf, Y., van Meurs, J. B. J., et al. 2004. "Genetics and biology of vitamin D receptor polymorphisms." Gene 338; 143-56.

[36] Stein, C. M. 2011. "Genetic epidemiology of tuberculosis susceptibility: impact of study design." PLoS Pathogens. 7(1):e1001189. doi:10.1371/jornal.ppat.1001189.

[37] Wilkinson, R. J., Liewelyn, M., Toossi, Z., et al. 2000. "Influence of vitamin D deficiency and vitamin D receptor polymorphisms on tuberculosis among Gujarati Asians in West London: a case-control study." Lancet. 355: 618-21.

[38] Velez, D. R., Hulme, W. F., Myers, J. L., et al. 2009. "NOS2A, TLR4, and IFNGRI interaction influence pulmonary tuberculosis susceptibility in African-Americans." Hum. Genet. 126: 643-53. doi:10.1007/s00439-009-0713-y.

[39] Ben-Selma, W., Harizi, H., and Boukadida, J. 2011. "Association of $T N F-\alpha$ and $I L-10$ polymorphisms with tuberculosis in Tunisian populations." Microbes. Infect. 13: 837-43.

[40] Takahashi, K., Hasegawa, Y., Abe, T., et al. 2008. "SLC11A1 (formerly NRAMP1 polymorphisms associated with multidrug-resistant tuberculosis." Tuberculosis. 88: 52-7.

[41] Van Crevel, R., Parwati, I., Sahiratmadja, E., et al. 2009. "Infection with Mycobacterium tuberculosis Beijing genotype strains is associated with polymorphisms in SLC11A1/NRAMP1 in Indonesian patients with tuberculosis." J. Infect. Dis. 200: 1671-4.

[42] Martineau, A. R., Wilkinson, K. A., Newton, S. M. et al. 2007. "IFN- $\gamma$ and TNF independent vitamin D inducible human suppression of mycobacteria: The role of cathelicidin-LL37." J. Immunol. 178: 7190-8. 